\title{
APRESENTAÇÃO DA EDIÇÃO ESPECIAL SOBRE GEOGRAFIA E AGRONEGÓCIO NO BRASIL
}

\author{
Dúlia Adão Bernardes ${ }^{\mathrm{A}}$ \\ Daniel Macedo Lopes Vasques Monteiro ${ }^{\text {B }}$ \\ ${ }^{\text {A }}$ Professora permanente do PPGG/UFRJ, Rio de Janeiro, RJ, Brasil \\ ${ }^{\text {B }}$ Doutorando do PPGG/UFRJ, Rio de Janeiro, RJ, Brasil \\ Recebido em: 10/12/2021 |21/12/2021 DOI: 10.12957/tamoios.2022.64084 \\ Correspondência para: Júlia Adão Bernardes e Daniel Macedo Lopes Vasques Monteiro (julia.rlk@gmail.com e \\ danielmlvm@yahoo.com.br)
}

Dentre os problemas que envolvem o agronegócio brasileiro destacam-se aqueles relacionados à divisão internacional do trabalho, a qual, segundo Eduardo Galeano, "consiste em que alguns países se especializam em ganhar e outros em perder" (GALEANO, 2000, p.15). Falando sobre a história do nosso continente em "As veias abertas da América Latina", Galeano assinala que a estrutura de classes criada, associada ao controle da terra, se perpetuou no poder, destruindo os recursos naturais e explorando a força de trabalho, enfatizando a resistência dos povos atingidos.

O modelo de exportações de commodities agrícolas, sem dúvida, apresenta êxitos notáveis, favorecido por políticas estatais que alteraram a estrutura de classes e o aparato produtivo. A integração técnica que conforma o complexo agroindustrial e a penetração do capital financeiro no campo favoreceu a emergência de um segmento de grandes e médios produtores capitalizados. Em contrapartida, significou o crescimento de um proletariado rural e a permanência da pequena produção agrícola nos espaços geográficos fronteiriços ainda preservados.

As palestras do curso "Geografia e Agronegócio no Brasil", realizadas por especialistas sobre temas específicos, no âmbito do Programa de Pós-Graduação em Geografia (PPGG) da Universidade Federal do Rio de Janeiro, no primeiro semestre de 2021, no formato remoto, um curso que obteve significativo número de inscrições de alunos da Pós-graduação das principais universidades do país, estão sendo publicadas neste número especial da Revista Tamoios na forma de artigos. Agradecemos aos responsáveis pela Revista, especialmente a Eduardo Karol, a receptividade e acolhida imediata para a publicação destes artigos. 
Além de resgatar tradições do pensamento social brasileiro, os artigos avançam em alguns aspectos relevantes do novo, a exemplo das formas de expansão da fronteira agrícola contemporânea e suas contradições, da difusão da técnica, dos circuitos espaciais da produção e dos círculos de cooperação, do avanço do capital financeiro no campo, das condições de trabalho, da nova organização das cidades do agronegócio, por vezes destacando a modernização do arcaico e a arcaização do moderno no âmbito da modernização (FERNANDES, 1977).

Entretanto, os textos marcam a co-presença de outros personagens no confronto com os interesses dominantes e as novas formas de produzir, a exemplo dos conflitos com os povos indígenas, com os assentados e posseiros. Nesse contexto, o conjunto do trabalho valoriza narrativas e experiências, reconhece sujeitos da ação, propondo uma leitura ativa do território (RIBEIRO, 2009).

Esta edição especial é iniciada com o artigo de Catia Antônia da Silva, o qual é dedicado a uma reflexão sobre o trabalho e o agir científico da Professora Júlia Adão Bernardes, que há mais de 30 anos pesquisa sobre a temática do agronegócio brasileiro na geografia. A autora revela a importância das pesquisas elaborada por Bernardes ao longo dessas décadas, mostrando uma análise, não só de sua produção científica, mas também de um importante registro da história da geografia brasileira e dos processos territoriais resultantes da dinâmica do campo e das cidades do país. Este artigo é uma singela e belíssima forma de homenagem, que é refletida nos trabalhos aqui expostos. Diga-se de passagem, que quase todos os autores desta edição são ou foram orientados por Júlia Adão Bernardes, ou de uma forma ou de outra, mantiveram uma relação estreita profissional no diálogo com suas pesquisas.

O segundo artigo, de Henrique Faria dos Santos, aborda o atual processo de consolidação do agronegócio globalizado brasileiro, fundamentado no neoliberalismo. Após analisar os antecedentes do referido processo em períodos anteriores, com base em autores consagrados, assinala que o processo de modernização rural revela "um caráter profundamente conservador e seletivo, do ponto de vista setorial, social e regional". Baseando-se em Yoris (2016, 2018a, 2018b), argumenta que o atual sistema agroalimentar, que pode ser denominado de agro-neoliberalismo, vem se estruturando a partir do entrelaçamento de renovadas alianças público-privadas, de novas estratégias técnico-econômicas que intensificam a exploração sócio-ecológica e de contenção de reações críticas, via discursos corporativos e governamentais de sustentabilidade, de segurança alimentar, de desenvolvimento econômico e direito à propriedade privada. O autor aponta para a necessidade urgente de políticas que contemplem uma reforma agrária efetiva no Brasil, que priorize o desenvolvimento social. 
O artigo de Luis Angelo dos Santos Aracri se pauta no debate teórico estabelecido por Milton Santos (1988; 2001; 2002; 2004), com base nos conceitos "circuito espacial da produção" e "círculos de cooperação", no âmbito do processo de modernização do setor agrícola brasileiro. O autor opta em focar, com mais especificidade, os "círculos de cooperação", os quais são definidos pelos fluxos de ordem imaterial. O artigo é desenvolvido com base na noção de "setor agrícola" estabelecida por Henry Bernstein (2011), enfatizando as mudanças tecnológicas e organizacionais no âmbito dos circuitos espaciais da produção e dos círculos de cooperação do agronegócio. Destaca o papel de agentes que se organizam em redes de cooperação, com o intuito de desenvolver pesquisas voltadas à modernização do setor, visando uma alta rentabilidade em todas as etapas.

O texto de Júlia Adão Bernardes constitui uma referência no que tange ao debate sobre fronteira agrícola no Brasil, resgatando a discussão teórica do conceito, trazendo as noções de Frederick Turner (1893) e Pierre Monbeig (1952). O debate é acrescido com as perspectivas de José de Souza Martins (2014) e da própria autora (2005), os quais constroem a base teórica para o entendimento do conceito desenvolvido no artigo. O texto foca no avanço do agronegócio em Mato Grosso, em direção à Amazônia, através dos eixos de expansão que seguem as rodovias. Fala sobre o movimento de destruição da floresta, de implantação do gado e dos grãos, enfatizando o desencontro entre as distintas temporalidades.

O artigo de Daniel Macedo L. V. Monteiro mostra como as fronteiras agrícolas avançam em espaços não conectados às redes globais de produção e de consumo, atingindo grupos que não se enquadram na lógica capitalista da expansão, avançando no processo de destruição através do desmatamento, da grilagem e do consumo exagerado de agrotóxicos, ocasionando a destruição do meio ambiente e afetando a saúde da população. Tal situação é reveladora da coexistência conflituosa de diferentes racionalidades.

A autora Bruna de Castro Dias Bicalho expõe, em seu trabalho, os componentes do atual processo de financeirização do campo, reconhecendo como as ações e práticas utilizadas pelos agentes financeiros são cada vez mais agressivas no meio agrário brasileiro. Procura demonstrar como a terra se torna um ativo financeiro, subordinando-se às leis do mercado. Calcado na teoria do ciclo de reprodução do capital, de Marx, o artigo demonstra as estratégias de acumulação do setor do agronegócio nacional e internacional, através da renda da terra.

Luiz Felipe Ferrari Cerqueira de Farias construiu seu texto objetivando estabelecer as relações entre o agronegócio e o trabalho. Sua pesquisa é rica em dados que apresentam e comprovam a subordinação da classe trabalhadora do setor no estado de Mato Grosso. O artigo analisa os fluxos migratórios da força de trabalho em direção ao estado, bem como as mudanças no perfil dos trabalhadores. Através das teorias propostas por Rui Braga (2012,) com base no debate sobre o "precariado" e o "estado permanente de inquietação social", o 
autor analisa as metamorfoses ocorridas no âmbito do trabalho no contexto de expansão da fronteira agrícola.

Ao discutir a temática "cidades do agronegócio", Denise Elias traz uma importante e rara contribuição para a pesquisa geográfica. A autora inicia seu artigo realizando um debate conceitual sobre "cidades do agronegócio", desenvolvida a partir da noção inicial de "cidade do campo", de Milton Santos (1988, 1993, 2000). Seu trabalho revela as possibilidades de investigação no que tange: à reestruturação produtiva da agropecuária, ao consumo produtivo do agronegócio, à composição do setor industrial, à dinâmica populacional, à dinâmica do mercado de trabalho, à reestruturação da cidade e às desigualdades socioespaciais na escala intra urbana. A operacionalização proposta por Elias tem muito a contribuir na metodologia dos diversos trabalhos e pesquisas que têm/terão o espaço urbano como enfoque central, ao analisar as temáticas que envolvem o agronegócio brasileiro.

Roberta Carvalho Arruzzo, Lívia Domiciano Cunha e Liziane Neves abordam, em seu artigo, as relações territoriais entre os povos indígenas, especificamente os Guarani e Kaiowá, e o agronegócio. Pautadas em autores como Robert Sack (1986), Claude Raffestin (1993) e Milton Santos $(1996 ; 1999 ; 2006)$ trabalham os conflitos territoriais existentes no estado de Mato Grosso do Sul. O artigo traz uma excelente explanação sobre as atuais ofensivas do agronegócio em relação aos povos indígenas, destacando as estratégias utilizadas para o desmonte de políticas públicas.

Os autores Jorge O. Romano, Thais P. Bittencourt e Ana Carolina A. S. Castilho desenvolvem, em seu trabalho, a operacionalização da análise do discurso através de Ernesto Laclau (2007; 2009; 2014), Chantal Mouffe (2014), Íñigo Galvan (2012) e George Lakoff (2014), objetivando compreender a estruturação do discurso de dois agentes importantes do agronegócio no país. Trata-se de Xico Graziano, um intelectual orgânico do agronegócio, politicamente atuante na defesa do setor e na construção de ofensivas àqueles que porventura venham a confrontar com os modus operandis do agronegócio brasileiro, e da Rede Globo de Televisão, especificamente no que concerne à campanha publicitária "Agro: a indústria riqueza do Brasil" com o conhecido slogan "Agro é pop, Agro é tech, Agro é tudo". O trabalho sintetiza a diversidade existente nas estratégias narrativas do agronegócio que convergem num mesmo horizonte final: a construção de uma agrossociedade brasileira.

À guisa de conclusão: em 1990, p.72, Eduardo Galeano escrevia, no livro "A descoberta da América (que ainda não houve)", o seguinte texto:

O Brasil, último país do mundo que aboliu a escravatura, pratica em grande escala a escravidão assalariada. Abastece de alimentos a outros países, porém a metade de suas crianças come menos do que o necessário. A ditadura social sobreviveu à ditadura militar. A economia aniquila mais gente do que a polícia...enquanto esta realidade continuar, e, enquanto continuar piorando, a democracia seguirá resultando 
algo assim como um espetáculo montado por e para uma ilustrada minoria de minorias.

O que diria Eduardo Galeano hoje, se estivesse vivo, sobre a situação brasileira em 2021, quando as estatísticas mostram que as maiores áreas agrícolas do país são destinadas à exportação? Entre 1990 e 2019 a área plantada de alimentos básicos (arroz, feijão e mandioca) foi reduzida em 50,08\%, enquanto a área destinada às commodities (soja, milho e cana-de-açúcar) aumentou 128,58\%. É importante destacar a expressiva exportação de soja e milho, que no período compreendido entre 2015 e 2019, variou em torno 40,28\%. A situação se agrava quando se considera a expressiva exportação de produtos essenciais alimentares da dieta da população brasileira, como o arroz e o feijão, que cresceu 2.296,66\%, entre os anos 2000 e 2019 (ALENTEJANO, 2021).

Segundo estimativas divulgadas pelo IBGE, em 2021, a população brasileira situa-se em torno de 213 milhões de habitantes. A pesquisa da Rede PENSSAN - Rede Brasileira de Pesquisa em Soberania e Segurança Alimentar e Nutricional, revelou que em abril de 2021, mais da metade da população, ou seja, 116,8 milhões de pessoas, vivem em situação de insegurança alimentar, sendo que 43,3 milhões, estão em insegurança alimentar moderada e 19 milhões em insegurança alimentar grave.

Os dados são reveladores de que o agronegócio não apenas exporta commodities, mas também alimentos essenciais. Agrava-se, dessa forma, a contradição entre o que eles anunciam, "que alimentam o mundo", e o que de fato realizam, na medida em que retiram da população brasileira os alimentos indispensáveis à sua sobrevivência, com o intuito de também exportá-los, privilegiando a acumulação de capital em relação à segurança alimentar.

\section{REFERÊNCIAS BILIOGRÁFICAS}

ALENTEJANO, Paulo Roberto Raposo. O avanço do agronegócio no Brasil: gestão produtiva ou produção da miséria? In: Mesa 16 do XIV Encontro Nacional de Pós-Graduação em Geografia. João Pessoa, 13 out. 2021. Disponível em: https://www.youtube.com/watch?v=toLK1_3WDpc Acessado em: 13 out. 2021.

FERNANDES, Florestan. "Problemas de conceituação das classes sociais na américa Latina". In: Raúl Benitez Zenteno (coord.), As classes sociais na América Latina, Rio de Janeiro, Paz e Terra, 1977.

GALEANO, Eduardo. As veias abertas da América Latina. Editora Paz e Terra, Rio de Janeiro, 1978.

GALEANO, Eduardo. A descoberta da América (que ainda não houve). Editora da Universidade/ UFRGS, Porto Alegre, 1990.

\section{COMO CITAR ESTE TRABALHO}

BERNARDES, Júlia Adão. MONTEIRO, Daniel Macedo Lopes Vasques. Apresentação da edição especial sobre geografia e agronegócio no Brasil. Revista Tamoios, São Gonçalo, v. 
18, n. 1, p. 1-6, 2022. Disponível em: https://doi.org/10.12957/tamoios.2022.64084. Acesso em: DD MMM. AAAA. 